\title{
A comparison of perinatal and infant mortality rates in British Columbia and Finland: Similarities and differences
}

\author{
Päivi Rautava $^{1}$, Anne Synnes ${ }^{2 *}$, Jennifer Claydon ${ }^{2}$, Jaakko Matomäki ${ }^{3}$, Mika Gissler ${ }^{4,5}$ \\ ${ }^{1}$ Turku Clinical Research Centre, Turku University Hospital, Turku, Finland \\ ${ }^{2}$ British Columbia's Women's Hospital, Vancouver, Canada \\ ${ }^{3}$ Pediatric Research Unit, Department of Pediatrics, Turku University Hospital, Turku, Finland \\ ${ }^{4}$ Faculty of Medicine, Centre for Child Psychiatry, University of Turku, Turku, Finland \\ ${ }^{5}$ National Institute for Health and Welfare, Helsinki, Finland \\ Email: paivi.rautava@utu.fi, ${ }^{*}$ asynnes@cw.bc.ca, jclaydon@cw.bc.ca, jaakko.matomaki@utu.fi, mika.gissler@thl.fi
}

Received 27 September 2012; revised 22 November 2012; accepted 4 December 2012

\begin{abstract}
Introduction: Despite similarities, perinatal and infant mortality rates between British Columbia, (BC) Canada and Finland differ. Key variables that may influence stillbirth, early neonatal, perinatal and infant mortality rates in BC and Finland were studied. Methods: After standardizing definitions, data for all births between 2001 and 2009 from provincial and national registries were used to compare perinatal outcomes between BC and Finland. Annual change was evaluated with regression analyses. Results: Births before 22 weeks gestation were excluded. All mortality rates per 1000 were lower in Finland vs BC (perinatal: 5.1 vs 6.2, stillbirth: 3.4 vs 3.9 , early neonatal 1.7 vs 2.4 , infant 2.9 vs 4.0 ; all $p<0.0001$ ). Multiple and preterm births were higher in $B C$ with lower mean birth weight. Annual mortality rates decreased in both countries during the study period. Prenatal visits were more frequent in Finland. Caesarean section rates were markedly lower and stable in Finland but higher and increasing in BC. Discussion: Differences in perinatal mortality rate definitions were found. Higher multiple birth and preterm birth rates in BC are affecting mortality rates. Finland's policy of single embryo transfer is a potential explanation. It is possible to have good perinatal outcomes and low caesarean section rates. Conclusions: The Finnish health care system may suggest possible solutions for improved perinatal outcomes. Lower per capita health care expenditures in Finland do not appear to have adversely affected perinatal outcomes.
\end{abstract}

Keywords: Perinatal Mortality; Infant Mortality; International Comparative Studies

${ }^{*}$ Corresponding author.

\section{INTRODUCTION}

Perinatal and infant mortality are considered key indicators of a nation's health and wellbeing. In a recent report by the Organization for Economic Co-operation and Development (OECD) comparing infant mortality rates between nations, Canada's ranking slipped from $6^{\text {th }}$ best in 1987 to $15^{\text {th }}$ in 1997 and $26^{\text {th }}$ in 2007 despite a fall in Canada's crude infant mortality rate from 6.3 deaths per 1000 live births in 1995 to 5.1 per 1000 live births in 2007. On the other hand, Finland has consistently had one of the lowest infant mortality rates: 3.9 per 1000 live births in 1995 decreasing to 2.7 per 1000 live births in 2007, ranking among the top 5 countries in the OECD reports [1].

In Canada, health is a provincial responsibility. In British Columbia (BC), the infant mortality rate is one of the lowest in the country, at 4.3 deaths per 1000 live births [2].

British Columbia and Finland have many similarities. They are similar in population and geography. Health services in both are provided primarily through a tax-funded universal health insurance system which facilitates the use of health care and decreases the variation in health care utilization and outcomes. Both also have a highly regionalized system of neonatal-perinatal care. In $\mathrm{BC}$ there are three tertiary level neonatal intensive care units (NICUs); the largest is at British Columbia's Women's Hospital. In Finland there are five tertiary care NICUs with small and statistically insignificant variation in mortality rates [3]. Despite these similarities, there are differences in the provision of health care between Finland and BC. Prenatal health care is provided primarily by physicians in BC. In Finland over 99.5\% of pregnant women use municipality based maternity health care services [4] run by public health nurses/midwives with physicians providing a supportive consultant role. In 
2009, health expenditure in Canada comprised $11.4 \%$ of the gross domestic product (GDP) in comparison with only $9.2 \%$ of the GDP in Finland. For OECD countries, health expenditures average $9.6 \%$ of GDP. (OECD 2011) [5].

Variations in the registration of births and definitions used to calculate perinatal and infant mortality are known to vary [6]. It is therefore important that any international comparisons of these rates consider these potential biases.

The goal of this study was to compare BC and Finnish stillbirth, early neonatal, perinatal and infant mortality rates from 2001 to 2009. A further goal was to identify key variables that may influence these mortality rates and potentially explain the lower mortality rates in Finland despite lower health care expenditures. Key variables chosen were preterm birth rate, low birth weight (LBW) $(<2500$ grams), very low birth weight (VLBW) $(<1500$ grams) and extremely low birth weight (ELBW) $(<1000$ grams) rates, proportion of multiple births, antenatal care, maternal age, smoking in pregnancy and Caesarean section rates.

\section{METHODS}

\subsection{Data Collection}

British Columbia data were obtained from the perinatal data registry (BCPDR) and, for early neonatal deaths and infant deaths, British Columbia Vital Statistics. The provincially funded data registry began in 1994 with full provincial data collection since 2000. Data are collected on perinatal outcomes, care processes and resources [7]. Perinatal data are collected from clinician completed standard BC perinatal forms and health records by hospital or perinatal database registry staff and entered into a hospital based registry. There are multiple quality checks including validation checks at the data entry software level, BCPDR period end checks and audits. Though data collection is voluntary, the registry captures approximately $99 \%$ of births registered by BC Vital Statistics.

Finnish data were obtained from the Finnish medical birth registry (MBR) Official Statistics on Births and Newborns containing information on all pregnancies ending in a live birth or stillbirth. The Finnish MBR is kept by the National Institute for Health and Welfare (THL). Obligatory data collection to THL occurs in all hospitals with deliveries. Missing births are supplemented from birth and death certificates. Information on perinatal deaths (stillbirths or deaths during the first week of life) has been revised and complemented from the Cause-of-Death Register maintained by Statistics Finland. In cases of conflicting or missing information, the registry data are confirmed and complemented from maternity hospital records. The registry includes maternal, obstetrical and social background, health care and medical interventions during pregnancy and delivery, as well as infant outcome at seven days of life. According to data quality studies of the MBR, the majority of the registry content corresponded well or satisfactorily with hospital record data $[8,9]$.

A review of the definitions in the two registries found that $\mathrm{BC}$ included births at 20 and 21 weeks completed gestational age and Finland did not. No other differences were found. Births at less than 22 weeks of gestation were therefore excluded from the BCPDR data. BC Vital Statistics derived perinatal and early neonatal death rates were not adjusted for this. All live births and stillbirths in the Finnish and BC registries from January 1, 2001 to December 31, 2009 were included. Miscarriages, defined as births of fetuses born at less than 22 weeks of gestation or having birth weight less than 500 grams and with no vital signs, were excluded from the study.

\subsection{Definitions}

Live births were defined as the complete expulsion or extraction from the mother, irrespective of the duration of the pregnancy, of a fetus in which there was breathing, beating of the heart, pulsation of the umbilical cord or unmistakable movement of voluntary muscle, whether or not the umbilical cord had been cut or the placenta attached.

Stillbirths were defined as the complete expulsion or extraction from the maternal body after at least 22 weeks of gestation or after attaining a weight of at least 500 grams of a fetus in which at birth, there is no breathing, beating heart, pulsation of the umbilical cord or unmistakable movement of voluntary muscle.

Stillbirth rate was calculated as the number of stillbirths during a calendar year $\times 1000$ divided by the total births during that calendar year.

Perinatal mortality rate was calculated as the number of stillbirths and early neonatal deaths during a calendar year $\times 1000$ divided by the total births during that calendar year.

Early neonatal mortality rate was calculated as the number of deaths among infants less than 7 days of age during a calendar year $\times 1000$ divided by total live births during that calendar year.

Similarly, infant mortality rate was the number of deaths among infants less than 1 year during a calendar year $\times 1000$ divided by total live births.

Preterm live births were defined as live births at least 22 weeks gestation but less than 37 completed weeks of gestation. In the case of multiple births, the gestational age of the first baby was used.

Gestation, measured in completed weeks, was calculated from the first day of the last normal menstrual pe- 
riod, early ultrasound and very rarely, when neither was available, by clinical estimate at birth.

Low birth weight (LBW) was defined as below 2500 grams, very low birth weight (VLBW) as below 1500 grams and extremely low birth weight (ELBW) as below 1000 grams. Birth weight was the first recorded weight of the newborn obtained after birth, expressed in grams.

The number of perinatal visits included primary care antenatal visits but did not include consultations and specialty clinic visits (e.g. Diabetes Clinic).

Maternal age was age calculated using mother's date of birth and delivery date.

Multiple births were defined as pregnancies in which more than one infant was born, whether live born or stillborn.

Caesarean section delivery included all deliveries that involved surgical incision of the abdomen and uterine walls and included both elective and emergent Caesarean sections.

Smoking during pregnancy was defined as smoking any amount of cigarettes at any time during the pregnancy and information was obtained from the medical chart.

Years were defined as calendar years using the date of delivery.

\subsection{Statistical Analyses}

Comparisons of dichotomous variables were analyzed using Chi-square test. Means, for birth weight and num- ber of prenatal visits, were compared using the t-test. Associations between time and continuous outcome variables were studied using linear regression analyses and associations between dichotomous outcome variables and time were studied using logistic regression analyses. These regression analyses were done separately for each country. P-values below 0.05 were considered statistically significant. Statistical analyses were done using SAS for Windows version 9.2.

\section{RESULTS}

Perinatal outcomes for the 376,999 births in $\mathrm{BC}$ and 520,557 births in Finland during the nine year period 2001-2009 are shown in Table 1. The exclusion of 20 and 21 week GA births in BC reduced the number of births by 908 . Stillbirth, perinatal, early neonatal and infant mortality rates were clinically and statistically significantly lower in Finland than in BC. Preterm, LBW, VLBW and ELBW rates were lower in Finland which likely explains the lower mean birth weight in BC. The mean number of recorded prenatal visits was higher in Finland. Smoking during pregnancy was less common in $\mathrm{BC}$. The Caesarean section rate was remarkably lower in Finland than in BC (16.5\% vs $29.1 \%)$. There were more prenatal visits in Finland than in $\mathrm{BC}$.

Stillbirth, perinatal, early neonatal and infant mortality rates fell significantly from 2001 to 2009 in both BC and Finland (Tables 2 and 3) which was statistically signifi cant except for stillbirth and perinatal mortality rates in

Table 1. Comparison of births in British Columbia and Finland 2001-2009.

\begin{tabular}{|c|c|c|c|c|}
\hline & & British Columbia & Finland & $\mathrm{p}$ \\
\hline Number of deliveries & Total & 371,255 & 514,495 & \\
\hline Maternal age & mean & 30.3 & 30.0 & 0.0001 \\
\hline Primiparity & $\%$ & 45.9 & 42.0 & $<0.0001$ \\
\hline Multiples & $\%$ & 3.03 & 2.89 & $<0.0001$ \\
\hline Smoking in pregnancy & $\%$ & 10.7 & 14.8 & $<0.0001$ \\
\hline Prenatal visits & mean & 9.3 & 13.8 & $<0.0001$ \\
\hline Caesarean & $\%$ & 29.1 & 16.5 & $<0.0001$ \\
\hline Preterm births & $\%$ & 8.55 & 5.19 & $<0.0001$ \\
\hline Number of babies & total & 376,999 & 520,557 & \\
\hline Birth weight & mean & 3399.9 & 3502.6 & $<0.0001$ \\
\hline Babies $<2500$ grams & $\%$ & 5.63 & 4.42 & $<0.0001$ \\
\hline Babies $<1500$ grams & $\%$ & 1.01 & 0.83 & $<0.0001$ \\
\hline Babies $<1000$ grams & $\%$ & 0.49 & 0.39 & $<0.0001$ \\
\hline Perinatal deaths $/ 1000$ & & 6.2 & 5.1 & $<0.0001$ \\
\hline Stillbirths/1000 & & 3.9 & 3.4 & $<0.0001$ \\
\hline Early neonatal deaths $/ 1000$ & & 2.4 & 1.7 & $<0.0001$ \\
\hline Infant deaths/1000 & & 4.0 & 2.9 & $<0.0001$ \\
\hline
\end{tabular}


Table 2. Annual change in perinatal outcome rates in British Columbia and Finland.

\begin{tabular}{|c|c|c|c|c|c|c|}
\hline & \multicolumn{3}{|c|}{ British Columbia } & \multicolumn{3}{|c|}{ Finland } \\
\hline & $\mathrm{p}$ & OR & $95 \% \mathrm{CI}$ & $\mathrm{p}$ & OR & $95 \% \mathrm{CI}$ \\
\hline Stillbirth & 0.0289 & 0.989 & $0.970-1.009$ & 0.333 & 0.991 & $0.973-1.009$ \\
\hline Perinatal death & 0.013 & 0.980 & $0.965-0.996$ & 0.060 & 0.986 & $0.972-1.001$ \\
\hline Early neonatal death & 0.004 & 0.963 & $0.939-0.988$ & 0.037 & 0.973 & $0.948-0.998$ \\
\hline Infant death & 0.026 & 0.978 & $0.959-0.997$ & 0.002 & 0.970 & $0.951-0.989$ \\
\hline Primiparae & $<0.0001$ & 1.013 & $1.010-1.015$ & 0.001 & 1.004 & $1.002-1.006$ \\
\hline Multiple births & $<0.0001$ & 1.016 & $1.008-1.023$ & 0.080 & 0.994 & $0.988-1.001$ \\
\hline Caesarean & $<0.0001$ & 1.025 & $1.023-1.028$ & 0.005 & 0.996 & $0.993-0.999$ \\
\hline Smoking & $<0.0001$ & 0.964 & $0.961-0.968$ & 0.663 & 0.999 & $0.996-1.002$ \\
\hline Preterm & $<0.0001$ & 1.017 & $1.013-1.022$ & 0.018 & 0.994 & $0.990-0.999$ \\
\hline LBW & $<0.0001$ & 1.013 & $1.007-1.018$ & 0.908 & 1.000 & $0.995-1.005$ \\
\hline ELBW & 0.342 & 0.992 & $0.974-1.009$ & 0.145 & 0.988 & $0.971-1.004$ \\
\hline \multicolumn{7}{|c|}{ Estimate/year standard error (SE) E/Y SE } \\
\hline Perinatal visits & 0.0005 & -0.037 & 0.007 & 0.0002 & -0.153 & 0.022 \\
\hline Birth weight & 0.001 & -5.350 & 1.023 & 0.0005 & -4.150 & 0.681 \\
\hline
\end{tabular}

LBW = low birth weight; ELBW = extremely low birth weight.

Table 3. Perinatal data from the years 2001-2009 in British Columbia and Finland.

\begin{tabular}{|c|c|c|c|c|c|c|c|c|c|c|c|c|c|c|c|c|c|c|}
\hline & $\begin{array}{c}\mathrm{BC} \\
2001\end{array}$ & $\begin{array}{c}\text { FI } \\
2001\end{array}$ & $\begin{array}{c}\mathrm{BC} \\
2002\end{array}$ & $\begin{array}{c}\text { FI } \\
2002\end{array}$ & $\begin{array}{c}\mathrm{BC} \\
2003\end{array}$ & $\begin{array}{c}\text { FI } \\
2003\end{array}$ & $\begin{array}{c}\mathrm{BC} \\
2004\end{array}$ & $\begin{array}{c}\text { FI } \\
2004\end{array}$ & $\begin{array}{c}\mathrm{BC} \\
2005\end{array}$ & $\begin{array}{c}\text { FI } \\
2005\end{array}$ & $\begin{array}{c}\mathrm{BC} \\
2006\end{array}$ & $\begin{array}{c}\text { FI } \\
2006\end{array}$ & $\begin{array}{c}\mathrm{BC} \\
2007\end{array}$ & $\begin{array}{c}\text { FI } \\
2007\end{array}$ & $\begin{array}{c}\mathrm{BC} \\
2008\end{array}$ & $\begin{array}{c}\text { FI } \\
2008\end{array}$ & $\begin{array}{c}\mathrm{BC} \\
2009\end{array}$ & $\begin{array}{c}\text { FI } \\
2009\end{array}$ \\
\hline Total babies born & 40,523 & 55,997 & 40,063 & 55,547 & 40,440 & 56,632 & 40,385 & 57,759 & 40,801 & 57,822 & 41,756 & 59,051 & 43,663 & 58,933 & 44,326 & 59,808 & 45,042 & 60,794 \\
\hline Total mothers* & 39,978 & 55,136 & 39,449 & 54,698 & 39,844 & 55,788 & 39,795 & 56,878 & 40,159 & 56,963 & 41,098 & 58,158 & 42,957 & 58,025 & 43,664 & 58,928 & 44,311 & 59,921 \\
\hline Mother's age (mean) & 30.0 & 29.9 & 30.1 & 29.9 & 30.2 & 30.0 & 30.3 & 30.0 & 30.4 & 30.0 & 30.4 & 30.0 & 30.4 & 30.0 & 30.4 & 30.1 & 30.5 & 30.1 \\
\hline Parity (primiparaes) $\%$ & 44.5 & 41.0 & 44.5 & 41.7 & 45.3 & 42.3 & 45.8 & 42.2 & 46.2 & 42.5 & 46.5 & 42.2 & 46.4 & 42.0 & 46.6 & 42.0 & 46.9 & 42.3 \\
\hline Birth weight (g) & 3427 & 3516 & 3411 & 3507 & 3406 & 3519 & 3397 & 3512 & 3388 & 3505 & 3382 & 3499 & 3383 & 3491 & 3390 & 3491 & 3380 & 3483 \\
\hline Birth length (cm) & 51.5 & 50.1 & 51.5 & 50.1 & 51.4 & 50.1 & 51.4 & 50.1 & 51.4 & 50.0 & 51.3 & 50.0 & 51.3 & 50.0 & 51.3 & 50.0 & 51.2 & 50.0 \\
\hline Twins $\%$ & 2.6 & 2.9 & 2.9 & 2.9 & 2.9 & 2.8 & 2.8 & 2.8 & 3.1 & 2.8 & 3.1 & 2.8 & 3.2 & 2.9 & 2.9 & 2.8 & 3.2 & 2.7 \\
\hline Triplets or more. $\%$ & 0.07 & 0.04 & 0.12 & 0.06 & 0.07 & 0.04 & 0.10 & 0.08 & 0.04 & 0.04 & 0.05 & 0.06 & 0.05 & 0.05 & 0.09 & 0.04 & 0.07 & 0.05 \\
\hline Multiples \% & 2.7 & 3.0 & 3.0 & 2.9 & 3.0 & 2.9 & 2.9 & 2.9 & 3.2 & 2.9 & 3.1 & 2.9 & 3.2 & 3.0 & 3.0 & 2.8 & 3.2 & 2.8 \\
\hline $\begin{array}{c}\text { Smoking in } \\
\text { pregnancy \% }\end{array}$ & 12.4 & 14.9 & 11.8 & 15.2 & 11.1 & 14.7 & 10.8 & 15.0 & 10.5 & 14.6 & 10.9 & 14.7 & 10.0 & 14.5 & 10.0 & 14.7 & 9.1 & 15.3 \\
\hline Prenatal visits (mean) & 9.4 & 14.3 & 9.4 & 14.4 & 9.4 & 14.1 & 9.4 & 13.7 & 9.3 & 13.8 & 9.3 & 13.8 & 9.2 & 13.7 & 9.1 & 13.3 & 9.2 & 13 \\
\hline Births $<37 \mathrm{GA} \%$ & 7.6 & 5.4 & 8.2 & 5.3 & 8.6 & 5.1 & 8.6 & 5.2 & 8.9 & 5.1 & 9.2 & 5.3 & 9.0 & 5.1 & 8.8 & 5.1 & 8.8 & 5.1 \\
\hline Babies $<2500 \mathrm{~g} \%$ & 5.2 & 4.5 & 5.6 & 4.5 & 5.5 & 4.3 & 5.6 & 4.4 & 5.8 & 4.3 & 5.8 & 4.5 & 5.9 & 4.5 & 5.7 & 4.3 & 5.7 & 4.5 \\
\hline Babies < $1500 \mathrm{~g} \%$ & 1.0 & 0.9 & 1.1 & 0.9 & 1.0 & 0.7 & 0.9 & 0.9 & 1.1 & 0.8 & 1.0 & 0.8 & 1.1 & 0.8 & 1.0 & 0.9 & 1.0 & 0.8 \\
\hline Babies < $1000 \mathrm{~g} \%$ & 0.5 & 0.4 & 0.6 & 0.5 & 0.6 & 0.3 & 0.4 & 0.4 & 0.6 & 0.4 & 0.5 & 0.4 & 0.6 & 0.3 & 0.5 & 0.4 & 0.5 & 0.4 \\
\hline Stillbirths/1000 & 4.3 & 3.8 & 4.2 & 3.8 & 4.0 & 3.2 & 3.3 & 3.2 & 3.5 & 3.2 & 4.3 & 3.3 & 4.3 & 3.5 & 3.8 & 3.2 & 3.6 & 3.6 \\
\hline $\begin{array}{l}\text { Perinatal deaths } \\
\text { VS \& PDR }{ }^{* *}\end{array}$ & 7.7 & 5.5 & 7.5 & 5.6 & 7.4 & 4.9 & 6.9 & 5.2 & 7.1 & 5.0 & 7.1 & 4.8 & 7.3 & 5.1 & 7.0 & 4.8 & 6.7 & 5.0 \\
\hline Early neonatal deaths-VS ${ }^{* *}$ & 2.6 & 1.7 & 2.5 & 1.7 & 2.6 & 1.7 & 2.7 & 2.0 & 2.6 & 1.8 & 2.0 & 1.6 & 2.25 & 1.6 & 2.0 & 1.4 & 2.0 & 1.4 \\
\hline
\end{tabular}

Years are calendar years based on babies date of birth; Late terminations are excluded; ${ }^{*}$ Babies linked to mothers; GA = Gestational age in weeks; $\mathrm{g}=\mathrm{Grams}$; $\mathrm{cm}=$ Centimeters; VS = Vital statistics; PDR= British Columbia perinatal database registry; ${ }^{* *}$ Infant death rates are taken from the BC Vital Statistics website. http://www.vs.gov.bc.ca/stats/annual/2009/xl/tab05.xls and The Finnish National Birth Register. http://www.stakes.fi/FI/tilastot/aiheittain/Lisaantyminen/synnyttajat/index.htm. 
Finland. The increase in prematurity rates in $\mathrm{BC}$ was associated with statistically higher LBW rates. The percentage of multiples increased by $1.6 \%$ per year in $\mathrm{BC}$ but not in Finland. The number of perinatal visits decreased in Finland by 0.22 visits per year with a clinically insignificant decrease of 0.04 visits/year in BC. The percentage of women who were primiparous increased significantly in both populations.

\section{DISCUSSION}

This study confirms that mortality rates are falling in both Finland and BC. It also provides insight into the differences in mortality rates between the two countries. The review of registry definitions revealed a difference in the lower gestational age limit threshold where BC included 20 and 21 weeks gestational age whereas Finland did not. In order to accurately compare, births below 22 weeks gestation were excluded from the data of both countries. However, because the number of babies excluded was small, this did not significantly affect the results. Perinatal and early neonatal death rates obtained from BC Vital Statistics could not be corrected but this is unlikely to have affected our results.

$\mathrm{BC}$ had higher rates of preterm birth and low birth weight births. As the most important reason for infant mortality in developed countries $[10,11]$, this is an important contributor to the observed difference in mortality rates.

The multiple birth rate increased in $\mathrm{BC}$ but not in Finland during the study period. Multiple births are associated with preterm births [e.g. 12], a fact that provides another explanation for the increase in infant mortality rates.

Multiple pregnancies can be spontaneous or associated with assisted reproductive technologies. Spontaneous multiple pregnancies are on the slight increase because of the progressively older age of expectant mothers [13]. With in vitro fertilization (IVF), there is an increased risk of preterm birth and perinatal mortality mainly due to the high incidence of multiple births associated with the transfer of multiple embryos [14]. Elective single embryo transfer (eSET), followed by one or several frozenthawed embryo transfer (FET) cycles, reduces the incidence of multiple pregnancies without adversely affecting pregnancy rates in both randomized controlled trials [14-16] and retrospective studies [17,18]. eSET is routine practice in Finland and the practice was implemented collegially by all 17 IVF units [19]. In Finland, SET has increased from $15 \%$ in 1992 to $68 \%$ of IVF treatments, $62 \%$ of intracytoplasmic sperm injection treatments and $62 \%$ of FETs in 2009 [20]. In 2005, Canada, had one of the highest rates of multiple deliveries $(29.9 \%)$ after IVF in the world [21], similar to that in the United States
(31.7\% in 2005). Janvier et al. calculated that, for Canada, a policy of single embryo transfer could prevent 30-40 deaths, 34 to 46 severe intracranial haemorrhages, and 13-19 retinal surgeries annually and NICU resources would be reduced by 5424 - 7299 patient-days of assisted ventilation and 35,219 to 42,488 patient-days of NICU care [21].

Our study also has important implications for health resource use and patient management. Finland has better perinatal outcomes with lower health care expenditures. The Finnish health care model of emphasis on health care prevention and the use of nurses and non physician health care workers for prenatal visits deserve further study. Whilst the proportion of Caesarean deliveries in $\mathrm{BC}$ has skyrocketed during our study period, Finland was able to maintain a $16.5 \%$ operative delivery rate suggesting that lower Caesarean section rates are possible and do not adversely affect mortality rates. This is consistent with several recent studies which showed an increased neonatal and maternal mortality with elective Caesareans compared with vaginal births [22-26].

Smoking rates during pregnancy were lower in BC. Data on smoking is susceptible to underreporting and ascertainment bias. The Finnish data show, however, similar smoking rates for pregnant women and the general population, where the female smoking rates were constantly between $16 \%$ and $20 \%$ during the study period (WHO Health for all-database). It is encouraging to notice that the proportion of parturients who quit smoking during the first trimester increased from $14 \%$ to $36 \%$ during the study period.

Our study used large population databases with clear definitions and a process of detailed data checks and validation. Referral biases and the smaller numbers associated with institutional studies were therefore avoided [27]. The research study team comprised Finnish and Canadian researchers with access and knowledge of both databases and their health care systems. Our team was therefore able to identify and correct for differences in definitions at the limits of viability $[6,28,29]$. Our data is current and captures recent trends.

The study was designed to compare differences in perinatal outcomes but it was not able to address causality. We did not have data on the cause of death, the proportion of single and multiple births that were conceived using assisted reproductive technologies and the reasons for Caesarean delivery. Health care costs were not collected. The results propose directions for further study.

\section{CONCLUSION}

Perinatal outcomes have improved in BC and Finland. Stillbirth, perinatal, early neonatal and infant mortality rates were clinically and statistically significantly lower 
in Finland than in BC. Multiple birth and preterm birth rates are higher in $\mathrm{BC}$ contributing to higher mortality rates. The effect of assisted reproductive technology practices on perinatal outcomes warrants further study. Lower per capita health care expenditures in Finland do not appear to have adversely affected perinatal outcomes.

\section{ACKNOWLEDGMENTS}

The authors acknowledge the BC Perinatal Data Registry managed by Perinatal Services BC for the contribution of data used in this research.

\section{REFERENCES}

[1] OECD (2010) Health at a Glance: Europe 2010. OECD Publishing. doi:10.1787/health glance-2010-en

[2] Perinatal Services BC. Perinatal Database Registry. http://www.perinatalservicesbc.ca/Perinatal\%20Database \%20Registry.htm

[3] Rautava, L. (2010) The effect of the birth hospital and the time of birth on the outcome of Finnish very preterm infants. Ph.D. Thesis, University of Turku, Turku. http://urn.fi/URN:ISBN:978-951-29-4279-4

[4] Malin, M. and Gissler, M. (2009) Maternal care and birth outcomes among ethnic minority women in Finland. BMC Public Health, 9, 84. doi:10.1186/1471-2458-9-84

[5] OECD Health Data (2011) Frequently requested data. http://www.oecd.org/document/16/0,3746,en_2649 3740

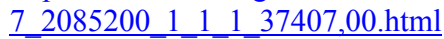

[6] Joseph, K.S., Liu, S., Rouleau, J., Lisonkova, S., Hutcheon, J.A., Sauve, R., et al. for the Fetal and Infant Health Study Group of the Canadian Perinatal Surveillance System (2012) Influence of definition based versus pragmatic birth registration on international comparisons of perinatal and infant mortality: Population based retrospective study. British Medical Journal, 344, e746.

doi:10.1136/bmj.e746

[7] British Columbia Perinatal Database Registry - Overview. http://www.perinatalservicesbc.ca//sites/bcrcp/files/Perin atal/OverviewBCPDRPamphlet.pdf

[8] Gissler, M., Teperi, J., Hemminki, E. and Meriläinen, J. (1995) Data quality after restructuring a nationwide medical birth registry. Scandinavian Journal of Social Medicine, 23, 75-80.

[9] Artama, M., Gissler, M., Malm, H., Ritvanen, A. and The Drugs and Pregnancy-Pilot Study Group (2011) Nationwide register-based surveillance system on drugs and pregnancy in Finland 1996-2006. Pharmacoepidemiology and Drug Safety, 20, 729-738. doi:10.1002/pds.2159

[10] Kurinczuk, J.J., Hollowell, J., Brocklehurst, P. and Gray, R. (2009) Inequalities in infant mortality project briefing paper 1. Infant mortality: Overview and context. National Perinatal Epidemiology Unit, Oxford. https://www.npeu.ox.ac.uk/files/downloads/infant-mortali ty/Infant-Mortality-Briefing-Paper-1.pdf

[11] Slattery, M.M. and Morrison, J.J. (2002) Preterm delivery. Lancet, 360, 1489-1497.

\section{doi:10.1016/S0140-6736(02)11476-0}

[12] Refuerzo, J.S. (2012) Impact of multiple births on late and moderate prematurity. Seminars in Fetal \& Neonatal Medicine, 17, 143-145. doi:10.1016/j.siny.2012.01.012

[13] Beemsterboer, S.N., Homburg, R., Gorter, N.A., Schats, R., Hompes, P.G. and Lambalk, C.B. (2006) The paradox of declining fertility but increasing twinning rates with advancing maternal age. Human Reproduction, 21, 15311532. doi:10.1093/humrep/del009

[14] Thurin, A., Hausken, J., Hillensjo, T., Jablonowska, B., Pinborg, A., Strandell, A., et al. (2004) Elective singleembryo transfer versus double-embryo transfer in vitro fertilization. New England Journal of Medicine, 351, 2392 2402. doi:10.1056/NEJMoa041032

[15] Van Montfoort, A., Fiddelers, A., Janssen, J., Derhaag, J., Dirksen, C., Dunselman, G., et al. (2006) In unselected patients, elective single embryo transfer prevents all multiples, but results in significantly lower pregnancy rates compared with double embryo transfer: A randomized controlled trial. Human Reproduction, 21, 338-343. doi:10.1093/humrep/dei359

[16] Thurin-Kjellberg, A., Olivius, C. and Bergh C. (2009) Cumulative live-birth rates in a trial of single-embryo or double-embryo transfer. New England Journal of Medicine, 361, 1812-1813. doi:10.1056/NEJMc0907289

[17] Van Montfoort, A.P., Dumoulin, J.C., Land, J.A., Coonen, E., Derhaag, J.G. and Evers, J.L. (2005) Elective single embryo transfer (eSET) policy in the first three IVF/ICSI treatment cycles. Human Reproduction, 20, 433-436. doi:10.1093/humrep/deh619

[18] Veleva, Z., Vilska, S., Hydén-Granskog, C., Tiitinen, A., Tapanainen, J.S. and Martikainen, H. (2006) Elective single embryo transfer in women aged 36 - 39 years. Human Reproduction, 21, 2098-2102. doi:10.1093/humrep/del137

[19] Nyboe Andersen, A., Goossens, V., Gianaroli, L., Felberbaum, R., de Mouzon, J. and Nygren, K.G. (2007) Assisted reproductive technology in Europe, 2003. Results generated from European registers by ESHRE. Human Reproduction, 22, 1513-1525. doi:10.1093/humrep/dem053

[20] Gissler, M. and Heino, A. (2010) Assisted fertility treatments 2009-2010. Official Statistics of Finland/Health, National Institute for Health and Welfare, Helsinki. http://www.stakes.fi/tilastot/tilastotiedotteet/2011/Tr15_1 $\underline{1 . p d f}$

[21] Janvier, A., Spelke, B. and Barrington, K.J. (2011) The epidemic of multiple gestations and neonatal intensive care unit use: The cost of irresponsibility. Journal of Pediatrics, 159, 409-413. doi:10.1016/j.jpeds.2011.02.017

[22] Kolås, T., Saugstad, O.D., Daltveit, A.K., Nilsen, S. and Øian, P. (2006) Planned cesarean versus planned vaginal delivery at term: Comparison of newborn infant outcomes. American Journal of Obstetrics and Gynecology, 195, 1538-1543. doi:10.1016/j.ajog.2006.05.005

[23] Declercq, E., Barger, M., Cabral, H.J., Evans, S.R., Kotelchuck, M., Simon, C., et al. (2007) Maternal outcomes associated with planned primary cesarean births com- 
pared with planned vaginal births. Obstetrics and Gynecology, 109, 669-677.

doi:10.1097/01.AOG.0000255668.20639.40

[24] Villar, J., Carroli, G., Zavaleta, N., Donner, A., Wojdyla, D., Faundes, A., et al., World Health Organization 2005 Global Survey on Maternal and Perinatal Health Research Group (2007) Maternal and neonatal individual risks and benefits associated with caesarean delivery: Multicentre prospective study. British Medical Journal, 335, 1025. doi:10.1136/bmj.39363.706956.55

[25] MacDorman, M.F., Menacker, F. and Declercq, E. (2008) Cesarean birth in the United States: Epidemiology, trends, and outcomes. Clinics in Perinatology, 35, 293-307. doi:10.1016/j.clp.2008.03.007

[26] MacDorman, M.F., Declercq, E., Menacker, F. and Malloy, M. (2008) Neonatal mortality for primary cesarean and vaginal births to low-risk women: Application of an "intention-to-treat" model. Birth, 35, 3-8.

doi:10.1111/j.1523-536X.2007.00205.x

[27] Field, D., Petersen, S., Clarke, M. and Draper, E.S. (2002) Extreme prematurity in the UK and Denmark: Population differences in viability. Archives of Disease in Childhood. Fetal and Neonatal Edition, 87, F172-F175. doi:10.1136/fn.87.3.F172

[28] Evans, D. and Levene, M. (2001) Evidence of selection bias in preterm survival studies: A systematic review. Archives of Disease in Childhood. Fetal and Neonatal Edition, 84, F79-F84. doi:10.1136/fn.84.2.F79

[29] Draper, E.S. (2010) Evaluating and comparing neonatal outcomes. Archives of Disease in Childhood. Fetal and Neonatal Edition, 95, F158-F159.

doi:10.1136/adc.2008.148213 